A collaboration between the JAOA and the American Association of Colleges of Osteopathic Medicine (AACOM) to recruit, peer review, publish, and distribute research and other scholarly articles related to osteopathic medical education.

\title{
JAOA/AACOM
}

\section{Public Health and Interprofessional Education as Critical Components in the Evolution of Osteopathic Medical Education}

H. Eduardo Velasco-Mondragon, MD, MS, PhD; Teresita Menini, MD; Catherine West, MD, $\mathrm{MPH}, \mathrm{DrPH}$; Michael Clearfield, DO

From the Touro University College of Osteopathic Medicine-CA.

Financial Disclosures: None reported.

Support: None reported.

Address correspondence to

H. Eduardo VelascoMondragon, MD, MS, PhD, Touro University College of Osteopathic Medicine-CA, 1310 Club Dr, Vallejo, CA 94592-1187.

Email: h.eduardo.velasco@tu.edu Submitted February 1, 2017; revision received December 21, 2017 ; accepted January 5, 2018.
Public health and interprofessional education (IPE) are included among the osteopathic core competencies and Entrustable Professional Activities that should be reflected in osteopathic medical curricula. Cognizant of the importance of these 2 areas, Touro University College of Osteopathic Medicine-CA (TUCOM) has developed initiatives to advance them on campus as well as within its academic curriculum. The authors acknowledge the importance of incorporating public health content into osteopathic medicine as well as expanding IPE in the health professions as part of a larger project to impart a unique identity and relevance to osteopathic medical education at TUCOM. The authors describe TUCOM's public health and IPE initiatives and outcomes in the context of current and future relevance for osteopathic medicine. Future directions to assess the quality and impact of these programs that may be of value for other colleges of osteopathic medicine are also discussed.

J Am Osteopath Assoc. 2018;118(11):753-763, e96-e100 doi:10.7556/jaoa.2018.161

Keywords: interprofessional education, medical education, osteopathic medicine, public health

he medical profession is facing unprecedented challenges and demands to increase its effectiveness, contain costs, and provide quality education to improve the health of society in general. To this end, the importance of including undergraduate public health content in the medical curriculum has gained increased recognition. The Institute of Medicine recommends that all medical students have access to public health education and that additional integrated learning opportunities with public health students are available. ${ }^{1,2}$ Several initiatives and calls for action have been issued in the past on the importance of integrating public health in the medical school curriculum. $^{3}$ In November 2006, the Consensus Conference on Undergraduate Public Health Education ${ }^{4}$ was convened to implement public health education competencies in the health professions, including allopathic and osteopathic medicine.

Integrated care models have been shown to improve health outcomes and patient satisfaction. ${ }^{5}$ In the past, the reductionist focus of the medical profession has proven to be ineffective; physicians must operate in social and organizational contexts, in 
collaboration with other health care professionals and social workers. Interprofessional education (IPE) and practice is needed to effectively meet the health needs of the population. The World Health Organization defines IPE as "the education that occurs when students from two or more professions learn about, from, and with each other to enable effective collaboration and improve health outcomes." ${ }^{, 6,7}$ The mission of IPE is to change the culture of health care delivery and foster the ability of health care professionals to communicate and work effectively in multidisciplinary teams to improve patient care.

In 2009, six professional associations, including the American Association of Colleges of Osteopathic Medicine (AACOM) and the Association of American Medical Colleges (AAMC), formed the Interprofessional Education Collaborative ${ }^{8}$ to promote and advance the concept of IPE and to encourage the creation of activities designed to help prepare future members of the health care team to work in concert and improve health care outcomes. In 2011, an Expert Panel sponsored by the Collaborative issued a set of core competencies divided in 4 domains for IPE training; these domains were updated in 2016, as follows:

- values/ethics for interprofessional practice

- roles/responsibilities

n interprofessional communication

- teams and teamwork

Acknowledging the importance of public health and IPE, the AAMC and AACOM have developed related competencies $^{9}$ and Entrustable Professional Activities (EPAs). ${ }^{10,11}$ Interprofessional Education is now one of the Commission on Osteopathic College Accreditation standards (6.4.50) for all colleges of osteopathic medicine (COMs) (Table 1).

This paradigm shift is prompting a growing number of medical schools to integrate public health and IPE content into their medical curricula, as well as to offer dual medicine and public health degree programs. Eighty-four (59\%) of 141 US allopathic medical schools offer a joint MD/MPH program, ${ }^{12}$ whereas 15 (44.1\%) of 34 COMs offer a joint DO/MPH degree program. ${ }^{13}$ Public health grounding helps medical graduates understand the interrelationships of social determinants of health, epidemiology, preventive medicine, health education, health policy and planning, and the broader context of health implications of therapies. It also fosters a better understanding of the role of diversity and inclusion in the health care professions and highlights the importance of offering integrated and interprofessional care to patients in their communities.

\section{GROUPIE Background}

Touro University College of Osteopathic Medicine-CA (TUCOM) developed the GROUPIE program (Global health, Research, Osteopathic manipulative medicine and Obesity, Ultrasonography, Public health, IPE, and Empathy) to develop its brand and bestow distinguishing characteristics upon its graduates.

The GROUPIE areas are distinct with measurable outcomes and often overlap and enrich each other, as previously described by Clearfield. ${ }^{13}$ In addition, the GROUPIE elements intersect with other components; for example, thematic threads across the curriculumsuch as obesity prevention, mental health, and substance abuse - are offered in response to contemporary public health needs. The academic focus is complemented with strong research and community service components that also integrate public health and IPE.

This article chronicles TUCOM's public health and IPE initiatives currently underway, as well as their outcomes, including the 10-year experience (2006-2016) of the DO/MPH dual-degree program. We also discuss lessons learned and future directions.

\section{Public Health}

\section{Initiatives and Outcomes}

The public health emphasis at TUCOM includes programmatic, service, and curricular initiatives. In 2012, we fully affiliated with the 3 Federally Qualified Health 


\section{Table 1. \\ Logic Model for Developing the Public Health Curriculum at the Touro University College of Osteopathic Medicine-CA (TUCOM)}

\begin{tabular}{|c|c|c|c|c|c|}
\hline \multirow[b]{2}{*}{ Inputs } & \multicolumn{2}{|c|}{ Outputs } & \multicolumn{3}{|c|}{ Outcomes - Impact } \\
\hline & Activities & Participants & Short & Medium & Long \\
\hline $\begin{array}{l}\text { - Old curriculum } \\
\text { - Faculty feedback } \\
\text { - Student feedback } \\
\text { - Public health } \\
\text { competencies } \\
\text { - AACOM } \\
\text { competencies } \\
\text { - EPAs } \\
\text { - COMLEX-USA } \\
\text { blueprint }\end{array}$ & $\begin{array}{l}\text { - Curricular review } \\
\text { - Review of syllabi } \\
\text { - In-person meetings } \\
\text { and discussions } \\
\text { - TUCOM's Curricular } \\
\text { Master Matrix } \\
\text { - Pilot test sessions } \\
\text { - Obtain feedback } \\
\text { from stakeholders } \\
\text { - Assess curricular } \\
\text { alignment }\end{array}$ & $\begin{array}{l}\text { - Faculty } \\
\text { - Student } \\
\text { representatives } \\
\text { - Administrators } \\
\text { - Community }\end{array}$ & $\begin{array}{l}\text { - Alignment of } \\
\text { curricular } \\
\text { competencies } \\
\text { - Review of } \\
\text { teaching materials } \\
\text { - Innovation of } \\
\text { teaching practices } \\
\text { - Curricular } \\
\text { restructuring, } \\
\text { timing, content, } \\
\text { intensity } \\
\text { - Improved } \\
\text { assessments }\end{array}$ & $\begin{array}{l}\text { - COMLEX-USA Level } \\
1 \text { performance } \\
\text {. Improved learning } \\
\text {. Importance of public } \\
\text { health in the } \\
\text { curriculum } \\
\text { - Increasing DO/MPH } \\
\text { matriculation and } \\
\text { success rates } \\
\text { - Increasing public } \\
\text { health elective } \\
\text { participation }\end{array}$ & $\begin{array}{l}\text { Improved professional practice } \\
\text { focusing in social determinants of } \\
\text { health, health disparities, and } \\
\text { public health in general. } \\
\text { Improving the health of the public } \\
\text { at the population level } \\
\text { - Increased participation in public } \\
\text { health grant proposals } \\
\text {. Greater community engagement } \\
\text { - Improved understanding of the } \\
\text { scientific literature in terms of } \\
\text { research methods } \\
\text { Improved practice of } \\
\text { evidence-based medicine }\end{array}$ \\
\hline
\end{tabular}

Assumptions: The DO public health curriculum is not a full public health program. Limited time availability to implement the public health curriculum. The public health curriculum's aim is not only to teach to board examinations but to improve medical practice and serve the public, guided by competencies and EPAs. Public health is multidisciplinary and interprofessional.

External Factors: Follow-up of graduates is long term, and it may be difficult to assess long-term impact. Difficult to assess whether the DO admissions process attracts public health-inclined candidates. Different specialties require differing emphasis and utilization of public health. DO/MPH students and MPH graduates entering the DO program may find duplication of public health content in the DO program.

Abbreviations: AACOM, American Association of Colleges of Osteopathic Medicine; COMLEX-USA, Comprehensive Osteopathic Medical Licensing ExaminationUSA; EPA, Entrustable Professional Activity.

Centers in our county (Solano) that offer longitudinal health care services and function as community public health centers. These health centers afford TUCOM students access to those most in need of health care within our community while also availing the students of opportunities for public health initiatives and interventions. These initiatives include public health programs in HIV, tuberculosis, and preventive care.

As part of the family medicine rotation at the Solano County clinic sites, students are provided exposure to patients in both the tuberculosis and viral clinics. This exposure is part of a larger blend of experiences that help the students take a macro public health perspective, which in turn helps them better understand the individual patient's perspective. Interfacing with patients and helping them navigate the public health services available to them lends invaluable perspective as students hone their skills for delivering patient care.

As part of TUCOM's partnership with Solano County Public Health, we have developed additional initiatives. Using the National Diabetes Prevention Program (DPP) as a platform, Touro University California (TUCA) and Solano County Public Health agreed to build preventive care programs together and cross-train health care professionals. As a result, TUCOM has trained and mobilized certified lifestyle coaches. In addition, the county public health program found key community partnerships to place students in areas of greatest need. This 2-year joint effort has resulted in more than 300 coaches and 6 master trainers to help train new coaches. Student coaches thus get meaningful interprofessional applied public health experiences while serving the community and 
providing key professional development to help build skills to be better team members in future practice. This partnership has been recognized by the state and federal authorities as an ideal model of academic and public health partnership.

In 2017, TUCOM took this partnership one step further by creating the Mobile Diabetes Education Center (MOBEC). This 32-foot-long mobile center travels throughout Solano County and focuses on raising awareness of prediabetes and diabetes, specifically in areas where access is limited and health care needs are greatest. Through MOBEC, TUCOM provides free diabetes screenings and glucose and hemoglobin $\mathrm{A}_{1 \mathrm{c}}$ testing and offers much-needed initial education to help people take the first step toward health. The MOBEC also provides exercise classes and cooking demonstrations through the Dia-BEAT-it program to provide people with concrete steps to improve their health. This program, which has received financial support from the Sutter Health Foundation and Solano County Public Health, served more than 600 people in the first 6 months.
The curriculum at TUCOM is continuously being reviewed to keep up with recent trends in medical care and health care delivery, as well as to address student and faculty suggestions. In 2016, curriculum meetings were held monthly for 6 months, and faculty development sessions were offered to align the curriculum with the profession's competencies, to develop milestones and assessments, and to enhance the curriculum toward achieving EPAs (eAppendix 1). Separate meetings were conducted by public health and evidence-based medicine faculty to align the public health curriculum. These curricular mapping exercises have also been offered at faculty development workshops to streamline the curriculum using AACOM competencies and EPAs.

The Figure shows a master matrix that has been used to guide the curricular review process and faculty development activities. It includes program learning objectives adopted from the AOA's 7 osteopathic core competencies. ${ }^{9,14}$ The objectives are tabulated across organ systems, patient presentation, and physician task domains to map them to the COMLEX-USA

\begin{tabular}{|c|c|c|c|c|c|}
\hline & OMS I & OMS II & OMS III & OMS IV & Residency \\
\hline \multirow[t]{2}{*}{ GROUPIE } & \multicolumn{4}{|c|}{ Patient presentations, disease etiologies } & \\
\hline & \multicolumn{4}{|c|}{$\begin{array}{c}\text { Organ systems (cardiovascular, respiratory, reproductive, } \\
\text { musculoskeletal, dermatology, etc); osteopathic manipulative } \\
\text { medicine; doctoring }\end{array}$} & \\
\hline \multirow{4}{*}{$\begin{array}{l}\text { Program } \\
\text { Learning } \\
\text { Objective }^{\mathrm{a}}\end{array}$} & \multicolumn{4}{|c|}{ MILESTONES USING BLOOM'S TAXONOMY } & EPA \\
\hline & $\begin{array}{l}\text { Factual } \\
\text { (remember, } \\
\text { understand) }\end{array}$ & $\begin{array}{l}\text { Previous + } \\
\text { conceptual } \\
\text { (apply, } \\
\text { analyze) }\end{array}$ & $\begin{array}{l}\text { Previous + } \\
\text { procedural } \\
\text { (analyze, } \\
\text { evaluate) }\end{array}$ & $\begin{array}{l}\text { Previous }+ \\
\text { metacognitive } \\
\text { (create) }\end{array}$ & $\begin{array}{l}\text { "First-year } \\
\text { residents will } \\
\text { be proficient/ } \\
\text { skillful in..." }\end{array}$ \\
\hline & \multicolumn{4}{|c|}{$\begin{array}{l}\text { For each milestone, write course learning objective using } \\
\text { incremental Blooms taxonomy verbs. }\end{array}$} & \\
\hline & \multicolumn{4}{|c|}{ For each milestone, identify assessments. } & \\
\hline
\end{tabular}

Figure.

Curricular development matrix for osteopathic medical students (OMS) at Touro University College of Osteopathic Medicine (TUCOM). Program learning objectives are itemized into incremental milestones using Bloom's Taxonomy, which may branch out into course learning objectives for which respective assessments are identified throughout the 4 years of the curriculum, building toward Entrustable Professional Activities (EPAs). The TUCOM GROUPIE program provides TUCOM's

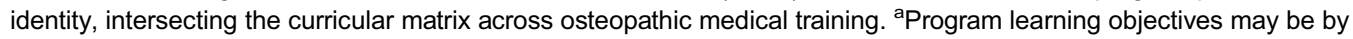
domain (eg, inflammation, neoplasia) or discipline (eg, anatomy, histology). 
blueprinting structure and therefore help prepare students for examinations. These domains are in turn converted into milestones that students must achieve across each semester of the program. Each milestone follows a progressive, incremental degree of complexity guided by Bloom's taxonomy and is assessed in formative and summative ways. At the end of the 4 years, these different, incremental milestones build up the curriculum matrix toward ensuring that students achieve EPAs on their first day of residency (Figure).

Cross-cutting this matrix is GROUPIE, which includes public health and IPE incremental milestones that must be accomplished by students toward EPAs specifically related to these areas. For example, for public health, the DO curriculum includes epidemiology, biostatistics, global health, health policy, evidence-based medicine, and electives (eAppendix 2). Work is still in progress to refine public health curricular content and outcomes. A challenge of the curricular review process is to roll a new curriculum over an old one, as students who start on one curriculum may be affected by having to adopt a new curriculum. It is particularly challenging when content moves between terms (together with curricular load and assessments), there are potential constraints of faculty availability, new teaching methods impose technical and space requirements, and faculty's academic freedom must be respected.

Curricular review for public health was developed using a logic model (Table 1). A similar example is presented for interprofessionalism, still in the making (eAppendix 3).

In addition to regular curricular content and in collaboration with other Touro schools, TUCOM offers a variety of elective courses with a public health focus that also often pertains to global health electives and IPE. Most of these courses, as follows, are offered university-wide:

- Healthcare Policy (BSCI 664)

- Fall Elective: Fundamentals of Global Health 1 (BSCI 668)
- Spring Elective: Fundamentals of Global Health 2 (BSCI 669)

- Children's Oral Health for Primary Care Providers

- Medical Nutrition (PRCR 651A)

- Social Justice in Public Health (BSCI 673)

\section{Dual DO/MPH Degree}

The focus on public health as a central and connecting theme at TUCA is evidenced by its dual-degree programs: PA/MPH, PharmD/MPH, and DO/MPH. The DO/MPH program started with the 2006-2007 academic year with 9 students. It provides an interdisciplinary academic program to develop competencies and skills in public health practice by integrating public health, health promotion, and clinical content areas and practice. ${ }^{15}$

To meet MPH program requirements, students must complete the equivalent of 42 credit units. However, students in the DO/MPH program, who may choose either the Community Health Track or the Global Health Track, must complete 30 or 31 units, respectively, from the MPH curriculum. They may transfer up to 12 units from the COM curriculum that fulfills corresponding public health competencies. Students in this program must complete a 200-hour field study for 2 credit units and a 3-unit capstone project. The public health program accepts 10 units from public healthrelated didactic courses of the DO curriculum and 2 units from its preventive medicine rotations.

Students may pursue the dual DO/MPH degree in 1 of 2 ways:

- Begin public health courses the summer before entering TUCOM. The didactic coursework will be completed during that first summer and the summer after the first year of the DO program. Students may then take the Certified in Public Health examination and complete their public health field study during rotations.

- Add a fifth year to the 4 years of osteopathic medical school. Students take a leave of absence from the DO program after completing their second year and the 
board examinations and spend a year immersed in public health. All didactic coursework is completed during the year, and the field study is completed during rotations.

According to AACOM data from the 2012-2013 academic year, the dual DO/MPH program at TUCOM had the most students enrolled (101), ${ }^{16}$ whereas other COMs reported between 8 and 18 dual DO/MPH degree students. Table 2 shows that the number of dual-degree students at TUCOM has increased over the years, with high graduation rates and acceptable grade point averages. Currently, about $10 \%$ to $20 \%$ of TUCOM students receive the DO/MPH; of those, $40 \%$ to $50 \%$ receive the MPH in global health.

To explore possible reasons for students enrolling in the DO/MPH program, in 2016 we compared the demographic and academic performance characteristics of enrolled and graduated students between 2010 and 2015 (88 of 95 graduated on time) with those of approximately 1005 non-dual-degree students. We also analyzed their choice of residency (AOA- vs ACGME-accredited program) and specialty (primary care vs other). There were no significant differences in student demographics, grade point average, AOA vs ACGME match, or primary care choice for residency between $\mathrm{DO} / \mathrm{MPH}$ and DO students (Table 3).

\section{Table 2.}

Number and GPA of DO/MPH Dual-Degree Graduates at the Touro University College of Osteopathic Medicine-CA ( $\mathbf{N}=95)$

\begin{tabular}{clll} 
Class of... & $\mathbf{n}$ & $\begin{array}{l}\text { Do/MPH Mean } \\
\text { Career GPA }\end{array}$ & $\begin{array}{l}\text { Graduated on } \\
\text { Schedule, No. }\end{array}$ \\
\hline 2010 & 2 & 3.35 & 1 \\
\hline 2011 & 11 & 3.53 & 10 \\
\hline 2012 & 16 & 3.52 & 16 \\
\hline 2013 & 20 & 3.51 & 20 \\
\hline 2014 & 21 & 3.49 & 19 \\
\hline 2015 & 25 & 3.51 & 22 \\
\hline
\end{tabular}

Abbreviation: GPA, grade point average.
Table 3.

Selected Characteristics and Residency Choices of DO/MPH and DO Students Through 2016

\begin{tabular}{lll} 
Characteristic & $\begin{array}{l}\text { DO/MPH } \\
(\mathbf{n = 8 8})^{\mathbf{a}}\end{array}$ & $\begin{array}{l}\text { DO } \\
(\mathbf{n = 1 0 0 5})\end{array}$ \\
\hline Age, y, mean (SD) & $33.2(4.1)$ & $32.6(4.5)$ \\
\hline Female, \% & 54.0 & 48.7 \\
\hline GPA, mean (SD) & $3.5(0.2)$ & $3.4(0.2)$ \\
\hline AOA Match participation, \% & 57.1 & 58.6 \\
\hline Primary care specialty, \% & 65.6 & 59.0 \\
\hline
\end{tabular}

a Data available for $88 \mathrm{DO} / \mathrm{MPH}$ dual-degree students, who graduated on time.

Abbreviations: AOA, American Osteopathic Association; GPA, grade point average.

\section{Interprofessional Education}

\section{Initiatives and Outcomes}

The university-wide IPE program that TUCA launched is evolving; within TUCOM, IPE is being developed through curricular and programmatic initiatives that provide our graduates the IPE competencies that are needed in professional practice. The IPE curriculum includes the annual IPE event, IPE laboratories, and a future interprofessional objective structured clinical examination (eAppendix 3).

To assess the attainment of curricular competencies, TUCOM regularly surveys its preceptors who are involved in the clinical education of third- and fourthyear students. In 2015 , the survey was sent to 1000 preceptors, and about $11 \%$ completed the survey. Although the low response rate limits the survey findings, with regard to students' interactions with the health care team, $81 \%$ of respondents agreed or strongly agreed that TUCOM students are adequately prepared to collaborate as members of the interprofessional team. Furthermore, $97 \%$ agreed or strongly agreed that TUCOM students are professional in their interactions with all members of the health care team, patients, and families. In the future, we will seek ways of improving response rates.

Every year, AACOM surveys graduates ${ }^{17,18}$ for their perspective on a number of issues related to 
their medical education and experiences, including time devoted to various areas of instruction. The surveys are mandatory, which provides AACOM with robust data. The 2015 graduating seniors survey report $^{17}$ showed that $40 \%$ of graduates at TUCOM participated in public health IPE activities, compared with only $15 \%$ of DO graduates nationwide. Additionally, $35 \%$ of TUCOM students participated in IPE community projects or service learning, compared with $22 \%$ nationwide.

In the 2016 report, ${ }^{18} 87 \%$ of TUCOM graduates thought that time devoted to public health instruction was appropriate, compared with $84 \%$ nationwide. Also, $56 \%$ of TUCOM graduates participated in public health and IPE activities, compared with only $18 \%$ nationwide. According to the survey, $78 \%$ of TUCOM graduates participated in IPE community projects or service learning, compared with only $65 \%$ nationwide. For the area of "teamwork with other health professionals," $87 \%$ of TUCOM graduates indicated that the time was appropriate, compared with $85 \%$ of DO graduates nationwide.

The AACOM survey also gathers the perspective of graduates on the evaluation of IPE. The following 2 statements are rated using a 5-point Likert scale, from strongly agree to strongly disagree:

- The learning experiences with other health professionals helped me to better understand the roles of other health professionals in patient care.

- I believe the learning experiences with other health professionals will contribute to/improve my performance as an osteopathic physician.

Although the 2015 survey revealed high agreement ( $\geq 90 \%$ ) with these statements from TUCOM and all other COMs, the 2016 survey found much lower rates of agreement (TUCOM, 66\% and 71\%, respectively; other COMs, $77 \%$ for both). Thus, this area is in need of curricular improvement for the TUCOM IPE program.

Faculty at TUCA have also created elective courses that can be attended by students from all colleges. The following courses represent some IPE electives:
- Social justice - Provides an introduction to topics of public health and social justice through a speaker series, allows viewing and analyzing segments of relevant documentaries, and engages discussion of social determinants of health.

- Narrative medicine - Engages with narratives in multiple media to deepen skills in listening, writing, observation, and critical analysis.

- Medical Spanish-Teaches Spanish grammar, medical vocabulary, and how to obtain a medical history and conduct a physical examination in Spanish.

\section{IPE Program}

Interprofessional education efforts started at TUCA in 2010, with the creation of a joint Faculty Senate and Administration IPE Leadership Committee that assembled members of all colleges on campus: osteopathic medicine, pharmacy, education and health sciences, and nursing. The IPE committee launched IPE events that incorporated the principles and competencies previously described and detailed by Mészáros et $\mathrm{al}^{19}$ in 2011.

The IPE Committee meets regularly to develop its annual program and includes different types of activities. For example, several university-sponsored IPE events are organized with participation of faculty and students from all colleges. These events focus on specific topics selected by the IPE committee because of their importance to our campus and our geographic area. The committee provided the necessary organization and training of the participating faculty who facilitated the student activities. These mandatory events facilitate the close interactions of students and faculty across colleges.

Each college conducts faculty development activities to inform and train faculty on the integration of IPE in the curricula. There are also many successful student-organized activities that include students from all colleges, different interdisciplinary clubs, and a student-run free clinic. At the clinic, students have the opportunity to practice their skills together, learn from each other, and work together to identify the best ways 
of integrating their professional abilities as they care for the underserved population. ${ }^{20}$ Students also participate in community-based health screening events.

A core component of TUCA's IPE program is based in public health. For example, the DPP, which is a 1 -year program, aims to reduce the progression to diabetes in people at high risk for this disease. This program offers IPE opportunities for DO, nursing, physician assistant, public health, and pharmacy programs to be certified as lifestyle coaches while working as a collaborative team. Certified lifestyle coaches across all disciplines go into the community and help people adopt therapeutic lifestyle changes. Of note, TUCOM is the first medical school in the nation to register with the Centers for Disease Control and Prevention to become a certified, university-accredited program.

Furthermore, TUCA has been able to use the DPP as an opportunity to provide hands-on practical IPE opportunities for its students. The DPP sessions are led by interprofessional teams of DO, nursing, physician assistant, and pharmacy students. Feedback from students has been positive and has resulted in a grant to provide a DPP mobile classroom to deliver this program to the most remote and medically underserved areas in the county.

\section{Discussion}

In this article, we sought to provide an overview of public health and IPE initiatives undertaken by TUCOM to respond to recent trends in medical education and health care delivery. For the past decade, TUCOM has strategically integrated public health into its didactics, both as core components of the curriculum and in a variety of elective study options, in addition to expanding the public health research focus and community service. The exposure to at-need populations and communities locally and globally allows all of our students an opportunity to delve into the individual, family, and public health issues that are likewise embedded within our curricular model. TUCA and TUCOM are also developing an IPE core to foster col- laboration among health care professionals. These initiatives are in turn integrated with TUCOM's GROUPIE initiatives, including research and service activities in the community and global health. ${ }^{13}$

\section{Public Health Lessons Learned and Future Directions}

Within the GROUPIE initiative, TUCOM has embraced public health as a way to enhance medical education and strengthen its primary care focus. Our curricular approaches include integration of public health and global health electives and the DO/MPH program with a curriculum that has been aligned with the current osteopathic core competencies and EPAs. According to AACOM data from the 2012-2013 academic year, TUCOM's DO/MPH program has the most students nationwide. However, the DO/MPH program is the only dual-degree program offered at TUCOM; should other options become available, as is the case for other COMs, it is possible that these numbers would decrease. At TUCOM's request and to obtain better data, AACOM added a couple of questions regarding dual-degree enrollment and completion to its annual graduating student survey:

- At any time during your osteopathic medical education, were you concurrently enrolled in another degree program?

- If you were, have you completed that additional degree?

The survey results did not identify the reasons underlying the popularity of the DO/MPH program among TUCOM medical students. Our dual-degree admissions process is not specially designed to attract dual-degree students, and there is no economic, tuition, or academic incentive offered beyond the opportunity of attaining a dual DO/MPH degree, often within the timeframe of obtaining a DO degree. During the admissions process, DO student candidates are introduced to the MPH program and, if interested, are encouraged to pursue the dual DO/MPH degree. All dual-degree candidates must meet the admissions criteria for both programs. 
Students may believe that the dual degree will help them with residency acceptance, expand their job opportunities in the future, and help align them with a public health vocation in addition to medicine. A question for future assessment is, Does TUCOM's admissions process attract or select students more inclined to pursue a dual DO/MPH degree?

To date, owing to the small number of dual-degree graduates, we have not been able to demonstrate whether dual-degree graduates are more inclined to pursue a public health career. However, we have been able to follow all of our alumni, which represent a larger, albeit still relatively small, number, given that TUCOM has only been in existence since 1997. In a 2014 survey of all California medical school graduates by the National Center for Analysis of Healthcare Data (unpublished data). TUCOM alumni represented the highest percentage of California-based alumni choosing a career in primary care, serving in rural areas, and serving the underserved. As noted in this analysis, TUCOM has far fewer alumni than other medical schools within the state, rendering findings more hypothesis-generating than definitive. However, given the success of the dual-degree program as an example of our emphasis on IPE and the alumni data to date, we are optimistic that our efforts will continue to support and grow the strong public health culture within TUCOM. A future outcome to be assessed would be whether our DO/MPH students pursue public health professional activities and careers.

In allopathic medical schools, the public health trends are mixed. The AAMC 2015 Medical School Graduation Questionnaire ${ }^{21}$ showed that $28 \%$ of medical graduates planned to participate in public health activities during their careers, compared with $25 \%$ in 2015. However, the AAMC 2014 Medical School Graduation Questionnaire ${ }^{22}$ showed that 27.1\% of MD graduates reported that their instruction in public health was inadequate, which represents an increase of about $5 \%$ over the previous 3 years. In addition, the 2015 survey demonstrated dwindling participation in public health activities by MD students, as explored by this question: "With which other profession(s) have you had the opportunity to participate or interact in educational activities?" Responses from years 2011 through 2015 show a downward trend in those years: $23.1 \%, 22.0 \%, 21.7 \%, 20.2 \%$, and $18.9 \%$, respectively.

Our curricular review of public health was very useful to streamline public health content along the continuum of the program. This review allowed us to confirm that we are accomplishing closer alignment with recommended public health competencies while identifying some gaps. However, a point of contention is the feasibility of adding public health content to an already packed medical curriculum. As may happen in other COMs, every semester new content areas (military medicine, opioid epidemic, new therapies, personalized medicine) emerge as priorities, but adding them may make the curricular load unmanageable for students. For example, TUCOM's curriculum includes only about 10 hours of epidemiology and biostatistics and a few hours of bioterrorism, which may be insufficient to cover content in these areas. Our evidencebased medicine curricular content further expands public health-related competencies. A similar challenge is faced in other public health areas, which impinge on the time and content of more traditional basic science and clinical disciplines. The college is trying to intersperse public health content as a disciplinary thread throughout the curriculum, which has the advantage of adding longitudinal intensity and repetition across the 4 years of the program. The dual DO/ MPH program is a reasonable alternative, albeit for a minority of students. Additional questions to assess outcomes include the following:

- Do DO/MPH graduates have better patient health outcomes?

- Do they show better professional competence and performance than their non-dual-degree counterparts?

- Are they more likely to serve diverse and underserved communities? 


\section{IPE Lessons Learned and Future Directions}

Touro University California has implemented a number of activities to promote interprofessional collaboration among students of the different schools in our campus. We have also discussed the possibility of creating an IPE curriculum across the schools. There are, however, many challenges to this approach. Even if students and faculty are enthusiastic about creating an IPE curriculum, the time dedicated to it will have to come from other courses, which inevitably will represent academic and logistical challenges. Also, the fact that different health sciences curricula are on different timelines makes coordinating them an additional challenge.

A new approach was initiated with the entering classes of 2015 to assess whether the creation of interprofessional teams starting on day 1 of enrollment and the assignment of small but regular collaborative activities for those teams is effective as a potential substitute for a formal IPE curriculum. An interprofessional objective structured clinical examination is also being considered as a future activity, as well as the incorporation in our AOA competency-based Clinical Performance Evaluation of a question regarding "collaboration with the medical team" for our students during third- and fourth-year clerkships. ${ }^{9}$

We learned through our experience with IPE on campus that there are important initial organizational aspects to be considered. Assembling a group of IPE champions in every campus program is essential. This group takes responsibility for designing activities such as faculty development sessions that highlight the importance of IPE and that serve as think tanks for planning and organizing activities. The implementation of a formal IPE curriculum vs multiple individual activities will depend on the particular curricula of COMs across the nation.

Other schools have similar public health and IPE initiatives, but direct comparisons of content and outcomes are not possible. For example, Western University of Health Sciences and the Edward Via College of Osteopathic Medicine have successfully developed and integrated IPE experiences into their own programs. Colleges of osteopathic medicine should come together with a systematic and unified programmatic and curricular approach to frame initiatives, identify outcomes, and develop measurements to evaluate the effectiveness and impact of both public health and IPE programs in osteopathic medical education. Future questions to assess outcomes include the following:

- Does the IPE curriculum prepare high-performing DO students?

- Will they interact appropriately in interprofessional teams?

- Which roles will they play in interprofessional health care teams?

- Will they have better patient health outcomes?

\section{Conclusion}

Recent trends toward integration of primary care using interprofessional teams and strengthening the public health component of medical curricula call for innovating medical education. On one hand, medical schools must keep up with the state of the art innovations in medical education and find new strategies that will allow integration of content in a highly compressed medical curriculum in a way that is both manageable and attractive to students. On the other hand, medical schools must exercise caution in adding too much content at the expense of neglecting the core basic and clinical sciences. To keep abreast of these trends, TUCOM is implementing a comprehensive approach to education, research, and service that includes public health and IPE, among other components of GROUPIE.

As TUCOM moves forward with the GROUPIE program, the public health and IPE components will remain a central focus connecting with the program's other areas of emphasis. This focus will include enhancing TUCOM's dual-degree program in both local and global public health initiatives to better prepare our students to meet the health care challenges they will face as physicians. It will be imperative to assess how these 
initiatives result in the perception of and actual value of the osteopathic medical profession to students, patients, and communities.

\section{Acknowledgments}

We acknowledge the different TUCOM departments and the public health program for providing data and relevant information to prepare this manuscript.

\section{References}

1. Gebbie K, Rosenstock L, Hernandez LM, eds. Who Will Keep the Public Healthy? Educating Public Health Professionals for the 21st Century. Washington, DC: National Academies Press; 2003.

2. The Future of the Public's Health in the 21st Century [report brief]. Washington, DC: Institute of Medicine; November 2002. http://iom. nationalacademies.org/ /media/Files/Report\%20Files/2002/The-Futureof-the-Publics-Health-in-the-21st-Century/Future \%20of\%20Publics $\%$ 20Health\%202002\%20Report\%20Brief.pdf. Accessed January 31, 2017.

3. Altekruse J, Goldenberg K, Rabin DL, Riegelman RK, Wiese WH. Implementing the Association of Teachers of Preventive Medicine's recommendations into the undergraduate medical school curriculum. Acad Med. 1991;66(6):312-316.

4. Riegelman RK. Undergraduate public health education: past, present, and future. Am J Prev Med. 2008;35(3):258-263

5. Heyeres M, McCalman J, Tsey K, Kinchin I. The complexity of health service integration: a review of reviews. Front Public Health. 2016;4:223.

6. Framework for Action on Interprofessional Education \& Collaborative Practice. Geneva, Switzerland: World Health Organization; 2010.

7. Interprofessional Education Collaborative Expert Panel. Core Competencies for Interprofessional Collaborative Practice. Washington, DC: Interprofessional Education Collaborative; 2011.

8. What is interprofessional education (IPE)? Interprofessional Education Collaborative website. https://ipecollaborative.org/about-ipec.html. Accessed September 27, 2018.

9. Osteopathic Core Competencies for Medical Students. Chevy Chase, MD: American Association of Colleges of Osteopathic Medicine; 2012. https://www.aacom.org/docs/default-source/core-competencies /corecompetencyreport2012.pdf?sfvrsn=4. Accessed January 31, 2017.

10. Core Entrustable Professional Activities for Entering Residency: Curriculum Developers' Guide. Washington, DC: Association of American Medical Colleges; 2014. https://members.aamc.org/eweb /upload/Core\%20EPA\%20Faculty\%20and\%20Learner\%20Guide.pdf. Accessed January 31, 2017.
11. Osteopathic Considerations for Core Entrustable Professional Activities (EPAs) for Entering Residency. Chevy Chase, MD: American Association of Colleges of Osteopathic Medicine; April 2016.

12. Directory of MD-MPH educational opportunities. Association of American Medical Colleges website. https://students-residents.aamc. org/applying-medical-school/article/directory-md-mph-educationalopportunities/. Accessed October 9, 2018.

13. Clearfield M. A path to osteopathic distinction: the Touro California GROUPIE program [editorial]. J Am Osteopath Assoc. 2017;117 (8):488-494. doi:10.7556/jaoa.2017.098

14. The Basic Documents for Postdoctoral Training. Chicago, IL: American Osteopathic Association; 2018. https://osteopathic.org/wp-content /uploads/2018/03/aoa-basic-document-for-postdoctoral-training.pdf. Accessed September 28, 2018.

15. Maeshiro R, Johnson I, Koo D, et al. Medical education for a healthier population: reflections on the Flexner Report from a public health perspective. Acad Med. 2010;85(2):215. doi:10.1097 IACM.0b013e3181c885d8

16. Allied Health and Graduate Programs 2012-2013. American Association of Colleges of Osteopathic Medicine website. https://www. aacom.org/docs/default-source/data-and-trends/2012-13-allied-healthand-GProg.pdf?sfvrsn=10. Accessed January 31, 2017.

17. AACOM 2014-15 Academic Year Survey of Graduating Seniors Summary. Chevy Chase, MD: American Association of Colleges of Osteopathic Medicine; 2016. https://www.aacom.org/docs/defaultsource/data-and-trends/2014-15-GSSSR.pdf?sfvrsn=e87b5497_16. Accessed September 27, 2018.

18. AACOM 2015-2016 Academic Year Survey of Graduating Seniors Summary. Chevy Chase, MD: American Association of Colleges of Osteopathic Medicine; 2016. http://www.aacom.org/docs/defaultsource/data-and-trends/2015-16-graduating-seniors-summary.pdf? sfvrsn=10. Accessed January 31, 2017.

19. Mészáros K, Lopes IC, Goldsmith PC, Knapp KK. Interprofessional education: cooperation among osteopathic medicine, pharmacy, and physician assistant students to recognize medical errors. J Am Osteopath Assoc. 2011;111(4):213-218.

20. Redmond $P$, Shane $P$, West $C$. The use of interactive case simulation to support cross-specialty teamwork and interprofessional education. Int J Case Method Res Assess. 2015;27(2):93-107.

21. Medical School Graduation Questionnaire: 2015 All Schools Summary Report. Washington, DC: Association of American Medical Colleges; 2015:26. https://www.aamc.org/download/464412/data /2015gqallschoolssummaryreport.pdf. Accessed January 31, 2017.

22. Medical School Graduation Questionnaire: 2014 All Schools Summary Report. Washington, DC: Association of American Medical Colleges; 2014:20. https://www.aamc.org/download/397432/data /2014gqallschoolssummaryreport.pdf. Accessed January 31, 2017.

๑ 2018 American Osteopathic Association 


\section{eAppendix 1.}

Public health and interprofessionalism competencies and Entrustable Professional Activities (EPAs) used at the Touro University College of Osteopathic Medicine-CA (TUCOM) based on the American Association of College of Osteopathic Medicine (AACOM) competencies and guidelines.

\section{Public Health}

Public Health Systems Competencies $^{9}$

- Apply understanding of the interaction of public health and health care systems in the practice of osteopathic medicine as it affects health promotion and disease prevention.

- Assess and address the determinants of health and illness factors contributing to health promotion and disease prevention

- Assess and address the factors influencing the use of health services.

- Apply basic public health principles, practices, and sciences to the practice of osteopathic medicine.

- Recognize differences among public health, epidemiologic, and individual systems in the use of resources and in the practice of osteopathic medicine.

- Recognize the impact of environmental influences on human health.

- Understand and apply knowledge of cultural differences to improve public health among divergent populations.

- Understand the role of health policy on populations and individuals. 7.

Interprofessionalism

Collaborate as a

Member of an

Interprofessional

Interprofessional Team

Practice-Based Learning

Collaboration

Competencies $^{9}$

$(\text { EPA } 9)^{10}($ p38)

- Act with honesty and

Understand that population health issues affect the health of patients and therefore identify sources of information about the needs and resources of the community.

- Interact and begin to work collaboratively with community agencies, professionals, and others to address population health issues (eg, disease and injury prevention). integrity in relationships with patients, families, and other team members.

- Respect the dignity and privacy of patients while maintaining confidentiality in the delivery of team-based care.

- Communicate one's role and responsibilities clearly to patients, families, and other professionals.

- Usually engage in required public health reporting.

- Cross-sects with EPAs 3 and

- Explain the roles and responsibilities of other care providers and how the team works together to provide care.

- Choose effective communication tools and techniques, including information systems and communication technologies, for facilitating interprofessional discussions and interactions that enhance team function.

- Give timely, sensitive, instructive feedback to others about their performance on the team; respond respectfully to feedback from team members.

- Identify team members' roles and the responsibilities associated with each role.

- Establish and maintain a climate of mutual respect, dignity, integrity, and trust.

- Communicate with respect for and appreciation of team members and include them in all relevant information exchange.

- Use attentive listening skills when communicating with team members.

- Adjust communication content and style to align with team member communication needs.

- Understand one's own roles and personal limits as a provider and seek help from other team members to optimize health care delivery.

- Help team members in need.

- Explain to team members appropriate use of osteopathic manipulative medicine.

- Prioritize team needs over personal needs to optimize delivery of care. 


\section{eAppendix 2.}

Example of curricular mapping of epidemiology, biostatistics, and evidence-based medicine (EBM) in the Touro University College of Osteopathic Medicine-CA curriculum for osteopathic medical students. The curriculum starts with a program learning objective (PLO), and incremental milestones are identified with their respective assessments throughout the 4 years of the curriculum, which builds toward Entrustable Professional Activities (EPAs). ${ }^{10}$ This example is restricted to epidemiology, biostatistics, and EBM, not the entire public health curriculum. Abbreviations: ARR, absolute risk reduction; NNH, number needed to harm; NNT, number needed to treat; NPV, negative predictive value; PICO, Population, Intervention, Comparison, Outcome; PPV, positive predictive value; RRR, relative risk reduction.

PLO6. Practice-Based Learning and Improvement: "How can I improve care for my patients?"

Graduating students will be competent in the application of evidence-based care, lifelong learning skills, and reflection and selfimprovement to continually improve the quality of the care they provide for patients.

\begin{tabular}{|c|c|c|}
\hline \multicolumn{3}{|l|}{ Fall OMS I } \\
\hline $\begin{array}{l}\text { Epidemiology and } \\
\text { biostatistics }\end{array}$ & 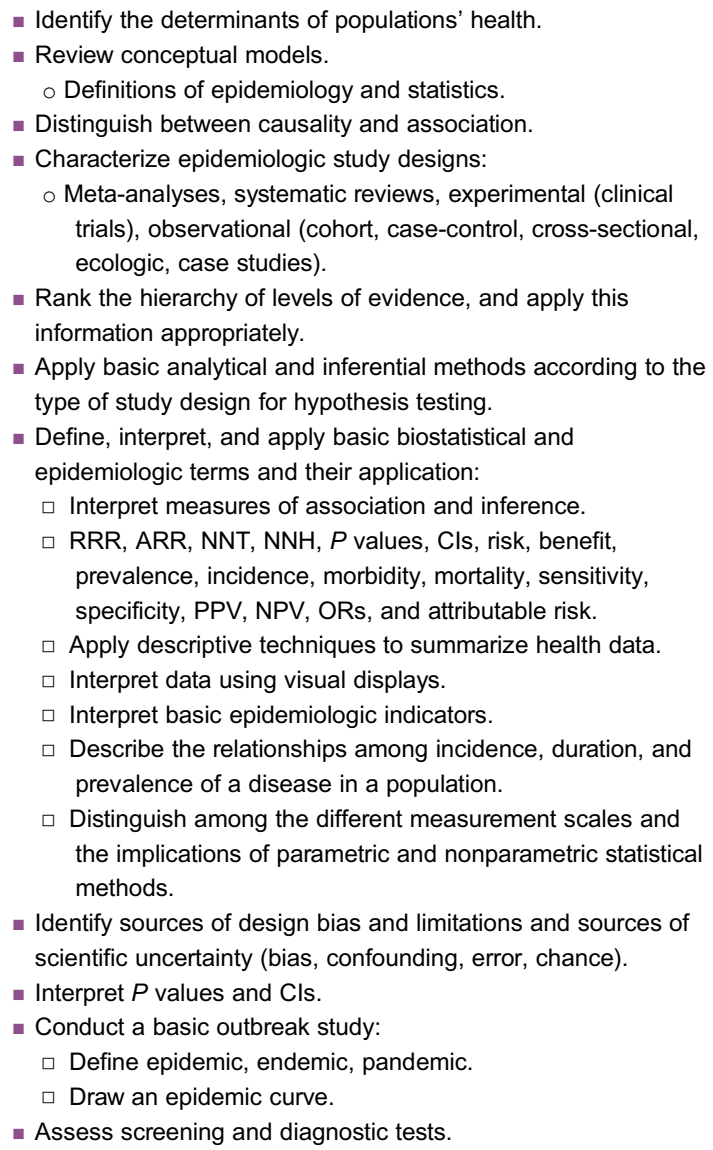 & $\begin{array}{l}\text { - Block } 1 \text { Theory Examination } \\
\text { - EpiStat } \\
\text { EpiStat Take-Home Quiz } \\
\text { - Attendance at EpiStat } \\
\text { lectures } 1-5 \\
\text { - Epistat longitudinal } \\
\text { paper-based exercise }\end{array}$ \\
\hline $\begin{array}{l}\text { Introduction to journal } \\
\text { clubs }\end{array}$ & $\begin{array}{l}\text { List, in order, the } 5 \text { "A"s in the Duke Cycle of Evidence. } \\
\text { Know how to formulate a clinical question using the PICO } \\
\text { format. } \\
\text { Identify the best study design based on the clinical question } \\
\text { you are asking. }\end{array}$ & \\
\hline
\end{tabular}


(continued).

\begin{tabular}{|c|c|c|}
\hline Curriculum Topic & Milestones and Course Learning Objectives & Assessments \\
\hline & $\begin{array}{l}\text { Describe how the following components of a research article } \\
\text { can influence its validity: } \\
\square \text { Authors and sponsorship. } \\
\square \text { Blinding and randomization. } \\
\square \text { Loss to follow-up/intention-to-treat analysis. } \\
\text { - Define Cls and } P \text { value and differentiate } P \text { value from effect } \\
\text { size. }\end{array}$ & \\
\hline Journal club 1 (treatment) & $\begin{array}{l}\text { - Evaluate the validity, results, and applicability of a therapy } \\
\text { study. } \\
\text { - Calculate and interpret the absolute risk reduction, relative risk } \\
\text { reduction, and NNT. } \\
\text { - Distinguish between statistical significance and clinical } \\
\text { significance. }\end{array}$ & $\begin{array}{l}\text { In-class journal club } \\
\text { assignment }\end{array}$ \\
\hline \multicolumn{3}{|l|}{ Spring OMS I } \\
\hline $\begin{array}{l}\text { Journal club } 2 \text { (diagnostic } \\
\text { tests) }\end{array}$ & $\begin{array}{l}\text { - Compare and contrast sensitivity/specificity with PPV/NPV and } \\
\text { likelihood ratios, with respect to influence of prevalence of } \\
\text { disease on calculations and epidemiologic scale. } \\
\text { - Evaluate the validity, results and applicability of a diagnosis } \\
\text { study. } \\
\text { - Calculate and interpret likelihood ratios. } \\
\text { - Convert a pretest probability to a posttest probability using } \\
\text { likelihood ratios. }\end{array}$ & $\begin{array}{l}\text { In-class journal club } \\
\text { assignment }\end{array}$ \\
\hline
\end{tabular}

\section{Fall OMS II}

Journal club 3 (Harm)

- Evaluate the validity, results, and applicability of a harm study.

In-class journal club

- Calculate and interpret OR and relative risk; interpret hazard assignment ratio.

- List factors that can increase the likelihood that an association is also a causal relationship.

- Calculate and interpret the number needed to harm.

\begin{tabular}{lll}
\hline Spring OMS II & & \\
\hline Journal club 4 (EBM in & $\quad$ Given a clinical scenario: & Evaluation of journal \\
practice) & $\square$ Formulate a clinical question. & presentation by facilitator rubric \\
& $\square$ Search for evidence in the primary literature. & \\
& $\square$ Appraise the research and its applicability. \\
& $\square$ Present these findings in a formal journal club setting. & \\
\hline
\end{tabular}

\section{OMS III-IV}

Core clinical clerkships and elective rotations
- Present a concise journal article evaluation including assessing the validity and magnitude of the results and consider the application of these results to a specific patient or population.

- Identify high-quality resources for scientific evidence.

- Acquire, appraise, and assimilate scientific evidence to answer clinical questions in the context of the management of individual patients.

\section{End of OMS IV}

- Describe and apply principles and practice of EBM.

- Interpret features and meanings of different types of data (quantitative, qualitative) and variables (including nominal, dichotomous, ordinal, continuous, ratio, and proportion).

- Recommend and interpret common diagnostic and screening tests (EPA 3). ${ }^{10}$

- Evaluate the relevance and validity of clinical research

- Describe the clinical significance of and apply strategies for integrating research evidence into clinical practice. 
(continued).

- Critically evaluate medical information and its sources, and apply such information appropriately to decisions relating to patient care.

- Form clinical questions and retrieve evidence to advance patient care (EPA 7). ${ }^{10}$

- Describe and apply systematic methods to improve population health. 


\section{MEDICAL EDUCATION}

\section{eAppendix 3.}

Example of curricular mapping of interprofessional education (IPE) in the Touro University College of Osteopathic Medicine-CA curriculum for osteopathic medical students. The program starts with a program learning objective (PLO), followed by incremental milestones with their respective assessments throughout the 4 years of the curriculum, which builds toward Entrustable Professional Activities (EPAs). ${ }^{10}$ For IPE, the goal is EPA 9: Collaborate as a member of an interprofessional team. ${ }^{10}$ Abbreviations: OMM, osteopathic manipulative medicine; OMS, osteopathic medical student; OPP, osteopathic principles and practice; OSCE, objective structured clinical examination.

PLO 7. Systems-Based Practice, Interprofessional Collaboration Competencies: "How should I interact with other health care providers?"

Graduating students will be able to work effectively in interprofessional teams.

\begin{tabular}{|c|c|c|}
\hline OMS I & $\begin{array}{l}\text { Identify the role and value of the different professionals } \\
\text { participating in health care teams. } \\
\text { Simulate participation in interprofessional teams providing } \\
\text { quality care to standardized patients and Student Run Free } \\
\text { Clinic. }\end{array}$ & $\begin{array}{l}\text { - Laboratory to identify the value of } \\
\text { team-building with students from other health } \\
\text { careers. } \\
\text { Interprofessional case study requiring } \\
\text { participation of different health professions. }\end{array}$ \\
\hline OMS II & $\begin{array}{l}\text { - Simulate participation as members of an interprofessional } \\
\text { team shadowing physicians in early clinical experience. } \\
\text { - Communicate with respect for and appreciation of team } \\
\text { members. } \\
\text { - Use attentive listening skills when communicating with team } \\
\text { members. }\end{array}$ & $\begin{array}{l}\text { Participation in campus-wide Annual } \\
\text { Interprofessional Event. } \\
\text { - IPE OSCE on obesity and other topics. }\end{array}$ \\
\hline OMS IV & $\begin{array}{l}\text { - Lead and coordinate activities in an interprofessional team } \\
\text { offering clinical care to patients. } \\
\text { - Understand one's own roles and personal limits as an } \\
\text { individual provider and seek help from the other members of } \\
\text { the team to optimize health care delivery. } \\
\text { - Help team members in need. } \\
\text { - Explain to team members appropriate use of OMM and OPP } \\
\text { in the treatment of patients } \\
\text { - Prioritize team needs over personal needs to optimize delivery } \\
\text { of care. }\end{array}$ & $\begin{array}{l}\text { Preceptor's observation and grading of IPE } \\
\text { skills. }\end{array}$ \\
\hline
\end{tabular}

